J. Clin. Chem. Clin. Biochem

Vol. 17, 1979, pp. 533-536

\title{
A Semi-automated Bratton \& Marshall \\ Micromethod for Determining Acetylator \\ Phenotype of Rabbits Using the Abbott Bichromatic Analyzer-100
}

\author{
By L.W. Whitehouse and C.J. Paul \\ Drug Research Laboratories, Drugs Directorate, Health Protection Branch, Health and Welfare Canada, Tunney's \\ Pasture, Ottawa, Ontario, CANADA K1A OL2
}

(Received August 21, 1978/February 7, 1979)

\begin{abstract}
Summary: A micromethod for the determination of acetylator phenotype using the method of Bratton \& Marshall ((1939) J. Biol. Chem. 128, 537-550) was adapted to the Abbott Bichromatic Analyzer (ABA-100). Advantages of this procedure include: (a) the requirement for small blood samples $(20 \mu \mathrm{l})$ making it a suitable pediatric method and eliminating the need for venipunctures; (b) elimination of tedious manual reading of absorbances of samples and mathematical manipulation of data by the automated capabilities of the ABA-100; (c) an increase in the accuracy of the assay by reading samples at two wavelengths thereby correcting for differences in background.
\end{abstract}

\section{Eine halbautomatische Bratton \& Marshall-Mikromethode zur Bestimmung des Acetylator-Phaenotyps von Kanin- chen mit dem Abbott Bichromatic Analyzer-100}

Zusammenfassung: Eine Mikromethode für die Bestimmung des Acetylator-Phaenotyps nach dem Prinzip von Bratton \& Marshall ((1939) J. Biol. Chem. 128, 537-550) wurde an den Abbott Bichromatic Analyzer (ABA-100) adaptiert. Die Vorteile dieses Verfahrens umfassen: (a) geringes Probenvolumen (20 $\mu 1$ Blut), weshalb die Methode für die Kinderheilkunde geeignet ist und Venenpunktion entfältt; (b) Wegfall des ermüdenden Ablesens der Absorptionen der Proben und Datenverarbeitung durch die automatisierten Möglichkeiten des ABA-100; (c) eine Verbesserung der Analysengenauigkeit durch Untergrundkorrektur infolge Messung bei zwei Wellenlängen.

\section{Introduction}

The $\mathrm{N}$-acetylation of chemical agents with an aromatic amine character such as isoniazid, hydralazine, phenelzine, procainamide, nitrazepam, and sulfanilamide derivatives have been shown to exhibit a genetically controlled polymorphism in both animals and humans $(1,2)$. This polymorphism in acetylation rate can alter the therapeutic efficacy and toxicity of these and other chemical agents biotransformed by this metabolic pathway. For the purpose of treating individuals more effectively, evaluating toxicological data more thoroughly and routinely phenotyping individuals in population genetic studies, a simple and rapid method of determining the acetylating ability of laboratory animals and/or humans using small blood samples would be desirable and useful. In the course of our studies on the toxicity of isoniazid it became necessary to routinely determine the acetylator phenotype of rabbits. The method of Bratton \& Marshall (3) using sulfadiazine as a substrate for the acetylating enzyme, was scaled down to a micromethod and semiautomated by utilizing the Abbott Bichromatic Analyzer's (ABA-100) capability to automatically read samples at two wavelengths and convert the differences in absorbance $(\Delta \mathrm{A})$ to $\mu \mathrm{g}$ sulfadiazine per milliliter of blood.

\section{Materials and Methods}

\section{Apparatus}

An Abbott Bichromatic Analyzer-100 (ABA-100, Abbott Scientific Products Division, South Pasadena, California, 91030) and a Cary-15 recording spectrophotometer equipped with a highintensity light source (Applied Physics Corp., Monrovia, California, 91016) were used for all absorbance measurements.

\section{Reagents}

Sulfadiazine, sodium nitrite, $\mathrm{N}$-l-naphthylethyle nediamine dihydrochloride, trichloroacetic acid and ammonium sulfamate were purchased from local suppliers. The sodium salt of sulfadiazine was prepared by mixing equimolar concentrations of an ethanolic solution containing $80 \mathrm{~g} / 1$ sodium hydroxide with 
an ethanolic solution of sulfadiazine. The resulting salt was washed with ethyl alcohol and dried under vaccum. An aqueous stock solution of sodium sulfadiazine equivalent to $200 \mathrm{mg}$ of sulfadiazine per liter was used for the preparation of working standards. The dosing solution, an aqueous solution of sodium sulfadiazine equivalent to $200 \mathrm{~g} / 1$ sulfadiazine, was administered at $0.1 \mathrm{ml} / \mathrm{kg}(20 \mathrm{mg} / \mathrm{kg})$ over a $60 \mathrm{~s}$ time period in the marginal ear vein of male New Zealand White rabbits $(1.8-3.5 \mathrm{~kg})$ deprived of food for $16-18 \mathrm{~h}$.

\section{Procedure}

Blood $(20 \mu \mathrm{l})$ was collected with micropipettes (Microcaps, Drummond Scientific Co., Acadian Instruments Ltd., Etobicoke, Ontario M9C $4 \mathrm{~V} 3$ ) from the opposite ear vein at 20,40 , 60,120 , and $180 \mathrm{~min}$ after dosing with sulfadiazine and immediately transferred to $10 \times 75 \mathrm{~mm}$ culture tubes containing $0.94 \mathrm{ml}$ of water. Following complete hemoly sis, proteins were precipitated with $0.24 \mathrm{ml}$ of trichloroacetic acid $(150 \mathrm{~g} / \mathrm{l})$ and the supernatants separated by centrifugation.

Aliquots $(0.5 \mathrm{ml})$ of blanks, standards and sample supernatants were transferred to clean $10 \times 75 \mathrm{~mm}$ culture tubes for the assay of free sulfadiazine. Reagent solutions were added to culture tubes using re/micropipettors (microre/pettor, Scientific Manufacturing Industries, Emeryville, California 94608). $50 \mu \mathrm{l}$ of freshly prepared aqueous sodium nitrite $(1 \mathrm{~g} / 1)$ was added, mixed, and the solution allowed to stand for 3 min followed by $50 \mu$ l of ammonium sulfamate $(5 \mathrm{~g} / \mathrm{l})$. After mixing again and allowing the mixture to stand for $2 \mathrm{~min}, 50 \mu \mathrm{l}$ of an aqueous solution of N-1-naphthylethylenediamine dihydrochloride $(1 \mathrm{~g} / \mathrm{l})$ was added. The contents were mixed, transferred to an ABA100 multicuvette and the color developed for $5 \mathrm{~min}$ then assayed with the ABA-100. The operating conditions for the ABA-100 were as outlined in table 1 . For comparisons on the Cary-15 the assay was scaled-up by five-fold.

Tab. 1. Instrument settings for the ABA-100 for the assay of sulfadiazine.

\begin{tabular}{ll} 
Power & On \\
Incubator & $30^{\circ} \mathrm{C}$ \\
Mode selection & Endpoint \\
Reaction direction & Up \\
Analysis time & $5 \mathrm{~min}$ \\
Carousel revolution & 2 \\
Filters & $550 / 650$ \\
Syringe plate & - \\
Sample size & - \\
Decimal setting & 000.0 \\
Calibration factor & Conc. of standard \\
& Absorbance $(\Delta \mathrm{A})$ \\
Zero & 0000 \\
\hline
\end{tabular}

For routine assays of blood for sulfadiazine the most convenient working standards were $1.667,0.833$ and $0.333 \mathrm{mg} / \mathrm{l}$ prepared respectively from $1.00,0.50$ and $0.20 \mathrm{ml}$ of stock sulfadiazine solution, $24 \mathrm{ml}$ of trichloroacetic acid $(150 \mathrm{~g} / \mathrm{l})$ and sufficient water to give a final volume of $120 \mathrm{ml}$. Blanks were similarly prepared with the exception that stock sulfadiazine was replaced with distilled water. When $0.50 \mathrm{ml}$ of the sulfadiazine working standards were assayed as described above they represented 100,50 and $20 \mathrm{mg} / 1$ of blood, respectively.

Data for the sulfadiazine standard curve and the sulfadiazine elimination curves from the blood were fitted by regression analysis using a Nova 800 minicomputer. Results obtained from the ABA-100 and the Cary-15 were compared using the unpaired Student $t$-test. Variance of the absorption coefficients were anålyzed by an F-test.

\section{Results and Discussion}

A scan of diazotized sulfadiazine between $450 \mathrm{~nm}$ and $650 \mathrm{~nm}$ showed a maximum absorption peak at $543 \mathrm{~nm}$ returning to the baseline at $650 \mathrm{~nm}$ (fig. 1). On the basis of this observation the 550/650 filter supplied with the ABA-100 was chosen for the assay of sulfadiazine. Standards equivalent to between 10 and $500 \mathrm{mg}$ of sulfadiazine per liter of blood were prepared in water and diazotized. The absorbance at $550 \mathrm{~nm}$ and the difference in absorbance $(\triangle A)$ at $550 / 650 \mathrm{~nm}$ were determined on the Cary15 and the ABA-100, respectively (fig. 2). Standard

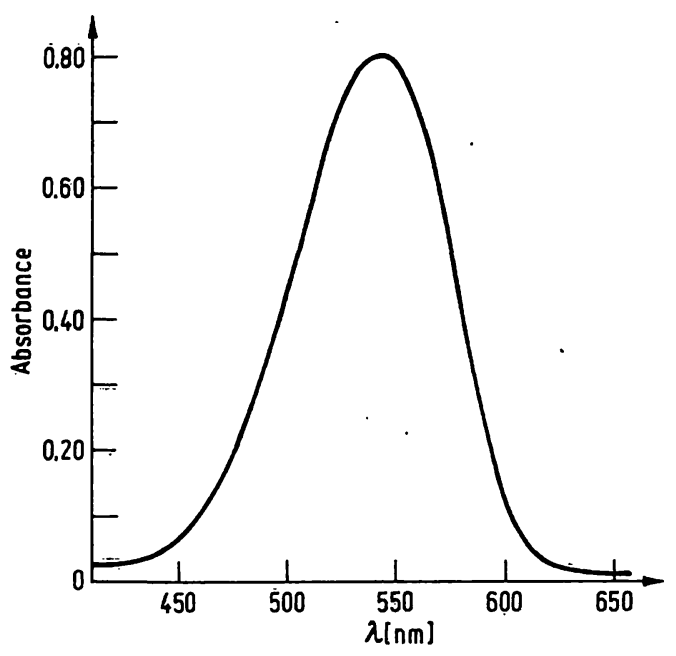

Fig. 1. Representative scan of diazotized sulfadiazine. Sulfadiazine $(3.85 \mathrm{mg} / \mathrm{l}$ final concentration) was diażotized as indicated in the materials and methods and scanned with a Cary-15 recording spectrophotometer between $450 \mathrm{~nm}$ and $650 \mathrm{~nm}$.

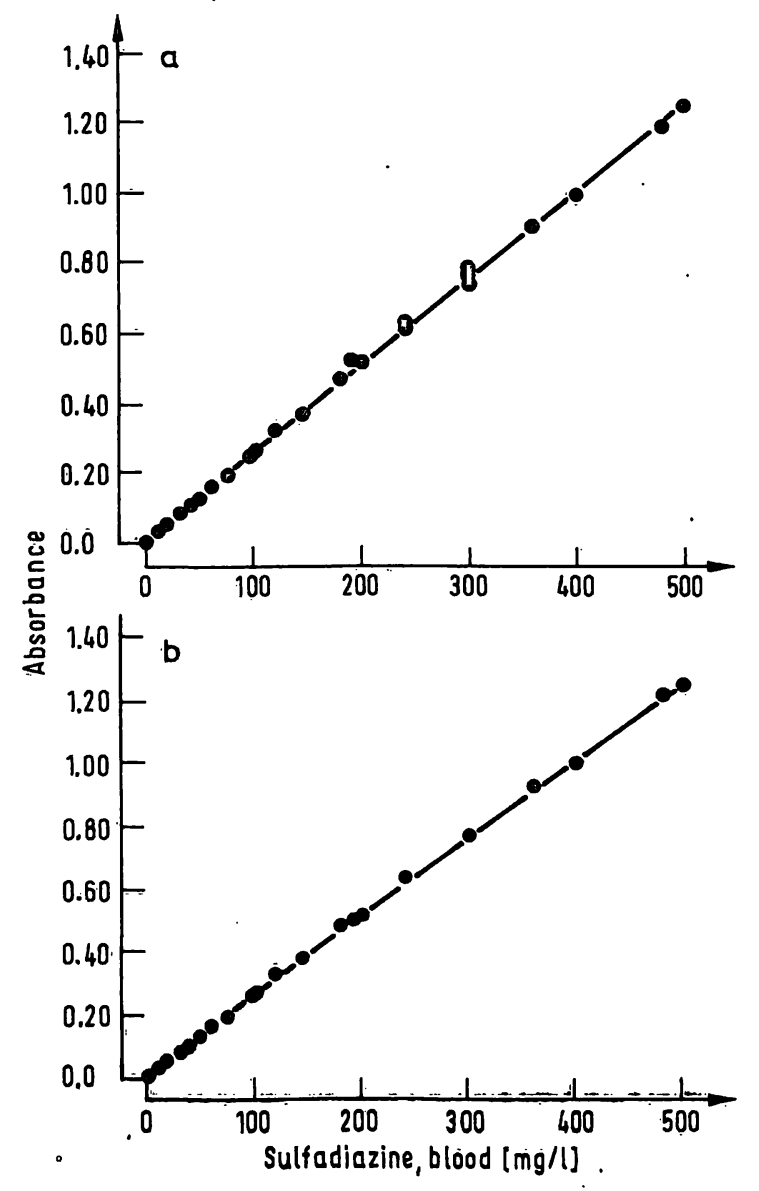

Fig. 2. Linearity of the standard curves assayed by a) the conventional method (Cary-15, $\lambda=550 \mathrm{~nm}$ ) and $b)$ the described method (ABA-100, filter 550/650). 
curves with their slopes, $Y$-intercepts and correlation coefficients were calculated (tab. 2). A statistical difference in the slopes and the Y-intercepts of the two standard curves could not be demonstrated. A slightly higher correlation coefficient was observed between the standard curve and the actual absorbance readings when the ABA-100 was employed, suggesting that the variance about the standard curve was less when the assay was performed with the ABA-100. Examination of the molar absorption coefficients $(\epsilon)$ calculated from data obtained with the two instruments indicated that the $\epsilon$ values were not significantly different, however the variance of $\epsilon$ was found to be statistically smaller (F-test) with the ABA100 (tab. 2). The higher correlation coefficient and the smaller variance observed with the ABA-100 was probably the result of (a) the elimination of the human error associated with the manual estimation of absorbances with the Cary-15 and (b) the bichromatic features of the ABA-100.

The coefficient of variation (CV) for the determination of sulfadiazine in blood using the ABA-100 is presented in table 3 . The overall $\mathrm{CV}$ was found to be $2.78 \%$ indicating this method to be a precise and reliable method for the determination of sulfadiazine in blood.

Using the ABA-100 method, sulfadiazine elimination profiles from the blood of male New Zealand White rabbits were examined. Typical elimination profiles from slow, medium and fast acetylator rabbits with the corre-

Tab. 2. A comparison of the standard curves from the Cary-15 and the $A B A-100$.

\begin{tabular}{llll}
\hline & Cary-15 & ABA-100 & Probabilitya \\
\hline Slope \pm SE & 0.002498 & 0.002489 & NS \\
& 0.000015 & 0.000013 & \\
Y-intercept & 0.01107 & 0.01478 & NS \\
& 0.00347 & 0.00337 & \\
Correlation & 0.99957 & 0.99966 & \\
coefficient & & & \\
Molar absorption & 50826 & 51317 & NS \\
coefficient $(\epsilon) \pm$ SE & 679 & 371 & \\
[l-mol $\left.{ }^{-1} \cdot \mathrm{cm}^{-1}\right]$ & & & \\
Variance of $\epsilon$ & $11.52 \times 10^{6}$ & $3.45 \times 10^{6}$ & 0.002 \\
CV $[\%]$ & 6.68 & 3.62 & \\
\hline
\end{tabular}

à Variance of $\epsilon$ analyzed by $\mathbf{F}$-test. All óther comparisons were made using the unpaired Student $t$-test.

Tab. 3. Estimation of the precision of the ABA-100 method for the determination of sulfadiazine.

\begin{tabular}{llll}
\hline Concentration (mg/l) & $n$ & Absorbance $\pm S E$ & $C V(\%)$ \\
\hline 400 & 5 & $1.028 \pm 0.005$ & 0.98 \\
200 & 5 & $0.530 \pm 0.004$ & 1.58 \\
100 & 5 & $0.273 \pm 0.001$ & 1.64 \\
50 & 5 & $0.133 \pm 0.002$ & 3.15 \\
10 & 5 & $0.031 \pm 0.001$ & 6.56 \\
\hline
\end{tabular}

sponding halflife, correlation coefficient and the elimination rate constant $(\mathrm{k})$ and its standard error are presented in figure 3 . The frequency distribution of sulfadiazine halflife in 137 rabbits is illustrated (fig. 4). Two groups of animals were differentiated by a half-life antimode at 60 to 70 min confirming Frymoyer \& Jacox's (4) earlier finding.

The intravenous route of administration of sulfadiazine was used in both this study and that of Frymoyer \& Jacox (4) and would be preferable for all phenotyping studies since the effect of absorption upon the apparent elimination rate from the blood could be avoided. How-

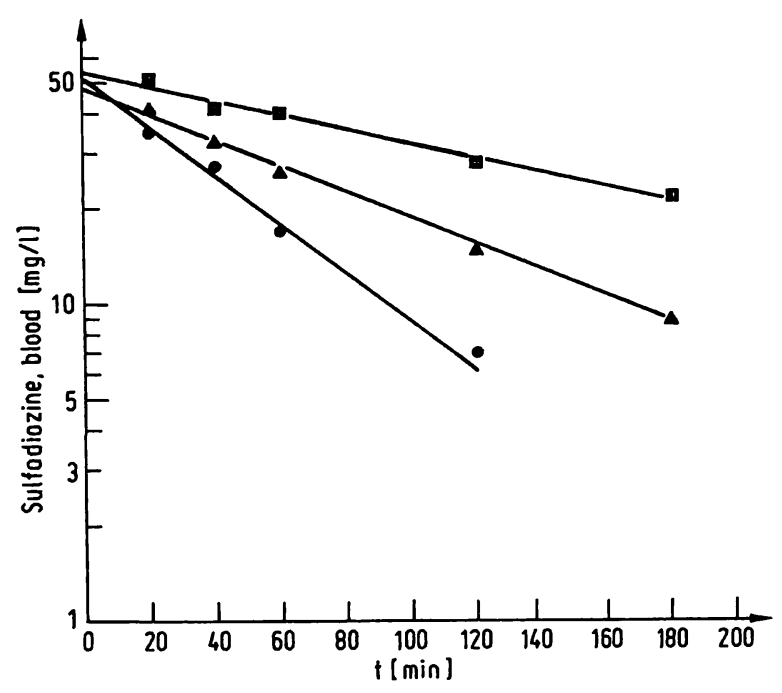

Fig. 3. Typical sulfadiazine elimination profiles from the blood of a slow $\left(\square, k=0.00514 \pm 0.0036 \mathrm{~min}^{-1} ; r=0.9927\right.$; $\left.t_{1 / 2}=135 \mathrm{~min}\right)$, medium $\left(\Delta, \mathrm{k}=0.00943 \pm 0.00038 \mathrm{~min}^{-1} ; \mathrm{r}=0.9975\right.$; $\left.t_{1 / 2}=74 \mathrm{~min}\right)$ and

fast $\left(\bullet, k=0.01805 \pm 0.00293 \mathrm{~min}^{-1} ; \mathrm{r}=0.9870\right.$; $\mathrm{t}_{1 / 2}=38 \mathrm{~min}$ )

acetylator male New Zealand White rabbit following the intravenous administration of sulfadiazine $(20 \mathrm{mg} / \mathrm{kg})$. The elimination rate constant (k) and its standard error, the half-life of free sulfadiazine $t_{1 / 2}$ and the correlation coefficient (r) for each of the animals were computed following regression analysis of the data from the ABA-100.

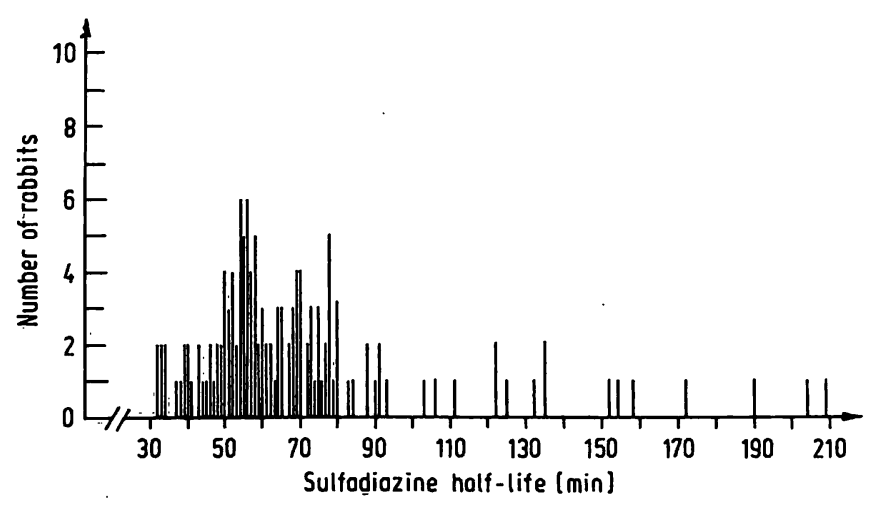

Fig. 4. Frequency distribution of sulfadiazine halflife in 137 male New Zealand White rabbits assessed by the described $A B A=100$ method. 
ever, intravenous administration of sulfadiazine or in fact any chemical agent to humans is associated with an additional patient-risk (hepatitis) and technological difficulties (the skills of a doctor or qualified nurse to make the actual intravenous injection). Recently Weber \& Brenner (5) and Hoo et al. (6) have published methods for the determination of acetylator phenotype in humans following oral administration of sulfamethazine, a dimethyl analogue of sulfadiazine. Since sulfadiazine and sulfamethazine are rapidly absorbed at similar rates from the gastrointestinal tract (7), it would appear that when circumstances dictate the oral route of sulfadiazine administration could be used to assess the acetylator phenotype of individuals. If the oral route of sulfadiazine administration is to be used to phenotype humans then the blood collection times must be adjusted so that they fall on the elimination phase of the blood profile curve. According to Olson et al (8), with a $10 \mathrm{mg} / \mathrm{kg}$ dose of sulfamethazine the absorption phase was complete by 3 hours. To prevent extended waiting periods for ambulatory patients and facilitate the phenotyping procedure, the number of blood collections could be reduced to two samples, perhaps a 3 and 4 hour sample. Since only $20 \mu \mathrm{l}$ blood samples are required for the assay, blood could be collected from finger or heel punctures avoiding the difficulties associated with venipunctures and making this a microsemi-automated method suitable for large scale population genetic studies.

The modified Bratton \& Marshall method described above offers a number of advantages over existing methods:

(a) The requirement for small blood samples $(20 \mu \mathrm{l})$ makes this a suitable pediatric method whereby sufficient blood can be obtained from a finger or heel puncture.

(b) The capabilities of the ABA-100 to automatically read absorbances and express results in terms of $\mathrm{mg}$ of sulfadiazine per liter of blood reduces the assay time considerably and circumvents tedious manual calculations.

(c) Absorbance differences in the baseline due to turbidity or cloudiness are corrected by the fact that samples are examined at two wavelengths (550/ $650 \mathrm{~nm}$ ) with the ABA-100 and the assay based on the differences between these two absorbance reading.

(d) By using the pharmacokinetic approach instead of a single blood sample, phenotype misclassification, a real possibility (9), is minimized.

\section{References}

1. Evans, D. A. P. (1968), Ann. N.Y. Acad. Sci. 151, 723-733.

2. Lunde, P. K. M., Frislid, K. \& Hansteen, V. (1977), Clin. Pharmacokinetics 2, 182-197.

3. Bratton, A. C. \& Marshall, E. K. (1939), J. Biol. Chem. 128, 537-550.

4. Frymoyer, J. W. \& Jacox, R. F. (1963), J. Lab. Clin. Med. 62, 891-904.

5. Weber, W.W. \& Brenner, W. (1974), Am. J. Hum. Genet. 26, 467-473.
6. Hoo, J.-J., Hussein, L. \& Goedde, H. W. (1977), J. Clin. Chem. Clin. Biochem. 15, 329-331.

7. Weinstein, L. (1970), In The Pharmacological Basis of Therapeutics, (Goodman, L. S. \& Gilman, A. eds.), pp. 11771203, The MacMillan Company, Toronto.

8. Olson, W., Miceli, J. \& Weber, W. (1978), Clin. Pharmacol. Ther. 23, 204-211.

9. Weber, W. W., Miceli, J. N., Hearse, D. J. \& Drummond, G. S. (1976), Drug Metab. Dispos. 4, 94-101.
Dr. L. W. Whitehouse Drug Toxicology Division Health Protection Branch Health and Welfare Canada Tunney's Pasture, Ottawa Canada, K1A OL2 